\title{
El rol de los migrantes en la dolarización de la economía ecuatoriana. Un análisis de su aporte
}

\section{The role of migrants in the dollarization of the ecuadorian economy. An analysis of your contribution}

German Gerson Huayamave

Universidad Santa María, Ecuador

Silvia Maribel Saltos Ronquillo

Universidad del Salvador, Argentina

Autor para correspondencia: ghuayamaveo@usm.edu.ec, silviamaribel.saltosronquillo@usal.edu.ar Fecha de recepción: 25 de Octubre de 2017 - Fecha de aceptación: 15 de Mayo de 2018

Resumen: El presente trabajo pretende describir de qué manera contribuyeron los migrantes ecuatorianos para el sostenimiento de la dolarización de la economía ecuatoriana. Para este efecto se detallará acerca de la crisis financiera, económica y política que soportó el Ecuador a finales de la década de los noventa, provocando que más de dos millones de ecuatorianos tomaran la decisión de migrar a países de mayor grado de desarrollo como España, preferentemente, así como a Estados Unidos e Italia, siempre en búsqueda de un empleo y un mejor nivel de vida para sus familias. Se expondrá acerca de las causas por las cuales, en el año 2000, el gobierno ecuatoriano, decidió cambiar el sistema monetario y dolarizar la economía nacional, debiendo devaluar previamente el sucre, con las consecuencias que debió afrontar la población. Asimismo, se evidenciará sobre las transferencias de dinero recibidas en el Ecuador por concepto de remesas enviadas por los migrantes ecuatorianos durante el periodo 2000 - 2015, y se establecerá una comparación de estos valores con el saldo de la balanza comercial ecuatoriana, lo que permitirá advertir el significativo aporte de la comunidad migrante ecuatoriana en el resguardo y fortalecimiento del actual sistema monetario, la dolarización que se apresta a cumplir dos décadas entre los connacionales.

Palabras Claves: crisis; economía; dolarización; migrantes; remesas; Ecuador

Abstract: This paper aims to describe how Ecuadorian migrants contributed to sustain the dollarization of the Ecuadorian economy. For this purpose, it will be detailed about the financial, economic and political crisis that Ecuador endured at the end of the nineties, causing more than two million Ecuadorians to take the decision to migrate to countries with a higher level of development such as Spain, preferably, as well as the United States and Italy, always in search of a job and a better standard of living for their families. It will be explained about the causes why, in the year 2000, the Ecuadorian government decided to change the monetary system and dollarize the national economy, having to previously devalue the sucre, with the consequences that the population had to face. Likewise, it will be evident about the money transfers received in Ecuador for remittances sent by Ecuadorian migrants during the period 2000 - 2015, and a comparison of these values will be established with the balance of the Ecuadorian trade balance, which will warn the significant contribution of the Ecuadorian migrant community in the safeguarding and strengthening of the current monetary system, the dollarization that is preparing to reach two decades among compatriots.to qualify its teachers, to empower and enrich the learning process in students with visual limitations

Key Words: crisis; economy; dollarization; migrants; remittances; Ecuador 


\section{Introducción}

Durante la década de los 90 surgieron varios factores en la economía ecuatoriana que ocasionaron una migración masiva de la población hacia diversos países desarrollados; siendo uno de estos factores la guerra entre Ecuador y Perú del año 1995, que afectó sobre todo a los habitantes de las provincias limítrofes de El Oro y Loja (Gómez, 2001).

Dicha guerra provocó que la situación económica del Ecuador se agrave, ocasionando incrementos en las tasas de interés superior al 100\%, además, debido al aumento de precios especulativos que demandaban más tenencia de efectivo al público, los cuenta ahorristas comenzaron entonces a retirar el dinero de los bancos como una manera de seguridad de sus recursos, porque visualizaban la situación interna que atravesaba el país, lo que originó el caos del sistema financiero. También, se creó un impuesto de guerra del $2 \%$ al rodaje de los vehículos, las exportaciones disminuyeron y se afectó el sector comercial y la inversión extranjera, ya que ninguna empresa quería invertir en un país que mostraba inestabilidad política y económica (Torres, 2000).

Estos acontecimientos llevaron a un incremento del desempleo y con ello un aumento en la pobreza, por lo que la situación se tornaba preocupante tanto para el gobierno como para la población ecuatoriana, que tenían que convivir con esta realidad que había dejado los estragos de la guerra, lo que ocasionó además, problemas sociales en el país, como la separación de las familias, ya que este escenario originó el inicio de la migración de muchos ecuatorianos a diferentes países del mundo, eligiendo entre los principales destinos a España, Estados Unidos e Italia.

En este sentido se puede indicar que para finales del año 1995, el saldo migratorio registró un total de 33,146 ecuatorianos que se encontraban fuera del país, mientras que a inicios de la década anterior, dicho número había sido de 14,400 (INEC-Ecuador, 1998)

Otro de los factores que causó el acelerado flujo migratorio de los ecuatorianos en esa época fue la crisis económica que afectó al Ecuador a finales del Siglo XX y que provocó que "el país experimentara el empobrecimiento más acelerado en la historia de América Latina. Entre el año 1995 y el 2000, el número de pobres creció de 3,9 a 9,1 millones; en términos porcentuales del 34\% al 71\%; y la pobreza extrema dobló su número de 2,1 a 4,5 millones" (Acosta, López, \& Villamar, 2005). En ese sentido podemos señalar como indicara Shaikh que el término "crisis" se refiere a un conjunto de fallas generalizadas en las relaciones económicas y políticas de reproducción capitalista (Shaikh, 1991, pág. 252)

En el año 1999 el gobierno declaró un feriado bancario que culminó con el congelamiento del total de los depósitos a plazo y la mitad de los depósitos a la vista. Esta enérgica medida, tuvo tal vez como único efecto positivo el freno temporal del incremento de la inflación y del tipo de cambio. Sin embargo, generó un enorme descontento social que deterioró aún más la institucionalidad y la situación general de la economía ecuatoriana (Banco Central del Ecuador, 2010).

Sumado a esto, la inestabilidad política del país ocasionado por los continuos cambios de gobiernos que se dieron durante esos años, tanto así que en el lapso de diez años (1996-2006) 
ejercieron el poder seis presidentes, cuyos periodos de gobiernos fueron interrumpidos antes de su legal culminación.

Como resultado de toda esta situación coyuntural por la que atravesaba el Ecuador durante la década de los 90, se produjo un descontento general en sus habitantes, así como también la desconfianza en el sistema financiero, debido al cierre de muchas instituciones bancarias principalmente. Además, la falta de empleo y el notable crecimiento del subempleo ocasionaron que las familias se volvieran más pobres y presionaron al pueblo ecuatoriano a tomar decisiones radicales para poder superar la crisis que se encontraban viviendo.

De esta forma, se inició un proceso continuo de emigración a finales del Siglo XX provocando que más de dos millones de ecuatorianos tomaran la decisión de migrar a otros países en búsqueda de un empleo y un mejor nivel de vida para sus familias. De acuerdo con los datos del INEC, el porcentaje de personas con ocupación plena durante el periodo 1992 a 1998 fluctuó entre el 32 y 39\%, en tanto que en 1999 se ubicó en $27 \%$, siendo el porcentaje más bajo de todo el período (Banco Central del Ecuador, 2010). Por esta razón el vertiginoso incremento de la salida de ecuatorianos se dio a partir del año 1999, registrando un saldo migratorio de 91,108 personas que migraron de Ecuador en ese año (INEC-Ecuador, 2000).

El 09 de enero del año 2000 el Gobierno del entonces Presidente ecuatoriano, Jamil Mahuad, como respuesta a la grave crisis económica, financiera, política y social, que atravesaba el país, decidió cambiar el sistema monetario y dolarizar la economía nacional, debiendo devaluar previamente el sucre, la moneda local, de forma extrema, con las consecuencias que debió afrontar la población ecuatoriana para lo cual fijó su tipo de cambio, que había flotado por cerca de 11 meses, y anunció que enviaría al Congreso los proyectos de ley requeridos para dolarizar completamente la economía del país (Beckerman \& Solimano, 2003, p. 35).

Empero, a pesar de la dolarización de la economía ecuatoriana, la inflación continuaba su marcada tendencia al alza, habiendo cerrado el año 2000 con una inflación anual del 96\% según cifras del Banco Central del Ecuador. La crisis era ya insostenible y afectaría a todos y cada uno de los ecuatorianos, situación que provocaría la avalancha de nacionales pugnando por un boleto aéreo que les permita abandonar el país con rumbo a España particularmente, nación que en ese entonces no les exigía visado alguno gracias al acuerdo de visados firmado entre ambos países en 1973.

Así, España se convertía en su norte, territorio donde les esperaría un futuro lleno de promesas ofrecidas básicamente por sus redes de familiares y amigos que ya habían salido del Ecuador durante la última década del Siglo XX, quienes los recibirían y apoyarían ante el abismo avizorado en su situación económica familiar en caso de permanecer en el Ecuador, por lo que la única alternativa factible era abandonar el país con rumbo a la nación ibérica.

Nace entonces una inmigración ecuatoriana que se incorpora a la sociedad española bajo condiciones de alta vulnerabilidad y precariedad social, debido a que los migrantes salen de Ecuador perseguidos por una situación de crisis económica que afecta al conjunto de la población y, de forma especial, al hecho de que se incorporan a la sociedad española como trabajadores con mano de obra barata y flexible que ocupan las posiciones más débiles de los 
sectores intensivos del modelo de crecimiento español (Iglesias, Moreno, Fernández, Oleaga, \& Vega, 2015, p. 21).

En este sentido podemos mencionar que este éxodo masivo de ecuatorianos hacia España a finales del Siglo XX, se lo puede comparar con lo mencionado en el trabajo de Miguez respecto a que la mano de obra barata y abundante era una necesidad vital para el capitalismo en expansión; en el caso inglés, donde la migración irlandesa constituyó "una importante reserva de trabajadores que alimentó a la vez, la demanda de mano de obra no calificada para la construcción en Londres, a mediados del Siglo XVIII, las ciudades fabriles en expansión de la revolución industrial, así como las cuadrillas de los trabajadores para la construcción de ferrocarriles, en la década de 1840 y 1850”. Dobb como se citó en (Miguez, 2009).

No obstante, de esta complicada situación circunstancial para la población migrante ecuatoriana las cosas ya eran muy distintas y para bien. En comparación con la realidad que atravesaban en el Ecuador, los migrantes alcanzaron a conseguir una plaza laboral que si bien era de muy baja calificación, tenían ya la primera situación que debían resolver debidamente atendida. Cabe mencionar que lograron de forma desorientada incorporarse al mercado laboral español, aunque fueron exclusivamente contratados para labores de menor competencia, como jornaleros en el campo, meseros y mucamas en la muy desarrollada hostelería ibérica, y obreros para el sector de la construcción de manera primordial.

Sin embargo, con el empleo obtenido por miles de compatriotas se generaría el mayor beneficio que recibiría el Ecuador entero fruto de esa masiva partida, el envío de las remesas necesarias para sustentar a sus familias, pero además y de forma simultánea para respaldar el proceso de dolarización de la economía ecuatoriana llevado adelante tras el feriado bancario de marzo de 1999.

Con estos antecedentes, el objetivo de este trabajo es determinar ¿de qué manera contribuyó el aporte de los migrantes ecuatorianos para el sostenimiento de la dolarización de la economía nacional durante el periodo 2000 - 2015?

\section{Metodología}

La metodología que se utilizará en esta investigación corresponde al enfoque cualitativo, considerando las características mencionadas por Hernández, en lo referente a que: "las investigaciones cualitativas se basan más en una lógica y proceso inductivo (explorar y describir, y luego generar perspectivas teóricas). Es decir, que van de lo particular a lo general" (Hernández R. , 2010, pág. 9).

Así también, se puede indicar que este trabajo se basa en un enfoque de tipo cualitativo al considerar lo señalado por Vasilachis, respecto a que la investigación cualitativa comprende el estudio, uso y recolección de una diversidad de materiales empíricos, como: estudio de caso, experiencia personal, historia de vida, entrevista, entre otros, que describen los momentos habituales y problemáticos y los significados en la vida de los individuos (Vasilachis, 2006, pág. 25). 
Además, este estudio será de tipo descriptivo, considerando la definición mencionada por Hernández, que indica que los estudios descriptivos buscan especificar las propiedades, las características y los perfiles de personas, grupos, comunidades, procesos, objetos o cualquier otro fenómeno que se someta a un análisis. Es decir, que sólo pretenden medir o recoger información de manera independiente o conjunta sobre los conceptos o las variables a las que se refieren (Hernández R. , 2010, pág. 80).

Así entonces, en este trabajo se espera describir la situación de la economía ecuatoriana a finales del Siglo XX, a fin de poder conocer de qué manera contribuyó el aporte de las remesas enviadas por los migrantes ecuatorianos para el sostenimiento de los primeros quince años de la dolarización de la economía nacional.

\section{Desarrollo}

La economía ecuatoriana se encuentra inmersa en el comercio internacional desde inicios del siglo pasado cuando logra posicionar uno de sus productos icónicos como una economía agroexportadora, la venta de cacao a los países europeos, principalmente a Francia, vincula al Ecuador en los inicios de una economía globalizada.

Las guerras mundiales desarrolladas en suelo europeo primordialmente ocasionaron graves problemas presupuestarios a la economía ecuatoriana, dependiente de las ventas de cacao, su principal producto de exportación; con posterioridad a la segunda guerra mundial, la venta de banano le permitió al Ecuador alcanzar la posición del mayor productor de banano del mundo, siendo los Estados Unidos y la Unión Europea sus principales mercados.

Desde inicios de los años setenta, el Ecuador encuentra reservas petroleras que permiten efectuar su exportación hasta la actualidad, constituyéndose en la principal fuente de ingresos de la economía ecuatoriana. Así, el Ecuador tiene un paulatino desarrollo de sus exportaciones hacia los principales destinos tales como Estados Unidos, la Unión Europea, Rusia y varios países asiáticos. A continuación se presenta el gráfico No. 1 donde se detalla el análisis de las exportaciones ecuatorianas de bienes FOB y el notable crecimiento de su volumen correspondiente a la última década del Siglo XX.

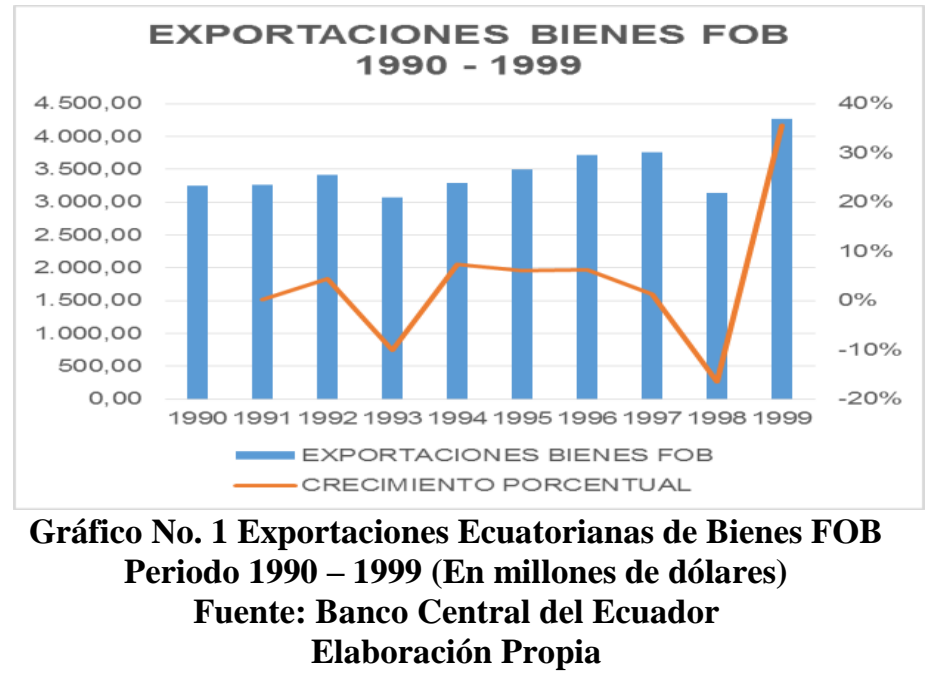


Gráficamente se puede notar que durante los años 1990 y 1991, las exportaciones de bienes FOB registraron un valor aproximado de \$3,260 millones de dólares; en 1992 las exportaciones fueron por $\$ 3,410$ millones, observando un incremento del $4 \%$, en comparación al año anterior, sin embargo, en el año 1993 la venta de productos ecuatorianos registraron una brusca caída del $10 \%$.

Durante el periodo 1994 - 1997 se observa una tendencia creciente del monto de las exportaciones ecuatorianas fruto de las permanentes devaluaciones del sucre; marcando un incremento porcentual del $7 \%$ en cada año. Luego es notoria la fuerte disminución de los montos de las exportaciones producto de la crisis financiera internacional del año 1998 que afectó a todas las economías del orbe, mostrando un crecimiento porcentual de $-16 \%$.

En el año 1999, las exportaciones de bienes FOB subieron considerablemente, situación que obedece a la crisis financiera enfrentada por el país, acompañada de una fuerte devaluación de la moneda ecuatoriana y el congelamiento de los depósitos, lo que restringió la liquidez de la economía y provocó una limitación en las importaciones. Así, en ese año se muestran ventas por $\$ 4,265$ millones de dólares, registrando un crecimiento porcentual del 36\% como se puede apreciar en la marcada pendiente positiva de este gráfico.

Sin embargo, durante esa época, los mercados mundiales a los que accedía el Ecuador enfrentaron ciclos económicos que en muchas ocasiones afectaban los ingresos esperados en el presupuesto general del estado, estos ciclos sumados a la fuerte competencia con los demás países de la región, productores normalmente de bienes y servicios similares a los que negocia la economía ecuatoriana, perturbaron las ventas de la producción exportable y disminuyeron los ingresos esperados por el gobierno ecuatoriano.

Ante esta situación de competencia regional, una de las opciones que se espera lograr para ganar los mercados es el aumento de productividad, opción que demanda fuertes inversiones en investigación y desarrollo, recursos con los que no cuenta el Ecuador, por lo que recurre de forma regular a la devaluación de su moneda local, que rinde un efecto similar en cuanto permite abaratar los precios de los productos exportados, pero tiene un gran efecto no deseado que repercute en la población, cuando la devaluación de su moneda ocasiona también la pérdida de poder adquisitivo de sus ciudadanos. Esta pérdida de poder adquisitivo provoca que la población sea cada vez más pobre perdiendo paulatinamente el poder de compra de bienes y servicios que tenían antes de la devaluación contemplada por las autoridades ecuatorianas.

Si bien se puede observar que durante el periodo 1990 - 1999, el monto de las exportaciones totales de los productos ecuatorianos se fueron incrementando anualmente logrando así la obtención de mayores ingresos para el país, la devaluación permanente de la moneda ecuatoriana como medida implementada por los gobiernos de turno para poder abaratar los costos de los productos exportables, ocasionaba sin embargo, que el Ecuador se vea inmerso en una de las mayores crisis económicas sufridas a finales del siglo pasado, debido a la pérdida del poder adquisitivo de la población que enfrentaba indicadores macroeconómicos deplorables, un descontento general en la población, desconfianza en el sistema financiero, variables que presionaban al pueblo ecuatoriano a tomar decisiones radicales para poder superar la crisis en que se encontraba sumida la economía nacional. 
De igual manera, durante los años noventa y la primera década del presente siglo, la economía ecuatoriana sufrió el impacto de algunos acontecimientos, tanto internos como externos. Entre los sucesos internos tenemos: el conflicto bélico de Ecuador con Perú, suscitado el 9 de enero de 1995 en el gobierno del Arq. Six to Durán, conocido como la Guerra del Cenepa y fue el resultado de intereses de tipo territorial que tuvieron origen en un conflicto llevado a cabo en 1941 entre esos países por una disputa fronteriza en relación a la soberanía del río Amazonas, y en la cual Perú salió victorioso; logrando que el 29 de enero de 1942 se firmara en la ciudad de Río de Janeiro el "Protocolo de Paz y Límites", donde Ecuador perdía alrededor de cinco mil millas cuadradas (Lekanda, 2009).

Sin embargo, el desarrollo de este nuevo conflicto no logró ninguna solución territorial, más bien hubo una intensa actividad diplomática que llevó a la culminación del problema mediante la negociación entre ambos países que terminaron con la suscripción del Acuerdo de la Paz en 1999.

Otro de los factores internos fueron los desastres naturales como el deslave de la Josefina ocurrido en el año 1993, considerado como el segundo desastre en magnitud en Suramérica después de la catástrofe ocurrida en el pueblo de Armero, en Colombia, en donde el cerro Tamuga, plagado de fallas geológicas, debilitado en la base por explotaciones mineras y sobrecargado de humedad por el invierno, se fue abajo la noche del 29 de marzo de 1993. El desplazamiento del cerro sepultó decenas de viviendas cuyos habitantes quedaron atrapados bajo tierra; destruyeron carreteras, fincas, sembríos y dañaron una central termoeléctrica valorada en 25 millones de dólares (Revista Avance, 1999).

Un nuevo desastre natural que sucedió durante los años 1997 y 1998 fue el Fenómeno de El Niño -un factor climático que azotó fuertemente a las plantaciones agrícolas en el país y ocasionó graves inundaciones en la Costa ecuatoriana- provocando un impacto económico para el país, debido a que miles de millones de dólares se perdieron por la destrucción de sembríos y por los daños en las carreteras.

Adicionalmente, al finalizar la década de los 90, Ecuador soportó una de las mayores crisis económica y financiera y enfrentó un proceso de inestabilidad interna, como consecuencia de varios problemas políticos ocasionados por los continuos cambios de gobierno con seis presidentes en el lapso de diez años (1996-2006) como fue el caso de Abdalá Bucaram que gobernó apenas seis meses y fue destituido por el Congreso Nacional por "incapacidad mental para gobernar" (Granda, 2004).

En 1997 Fabián Alarcón, Presidente del Congreso, fue nombrado Presidente Interino ante la declaración de juicio político iniciado contra el Presidente Bucaram y gobernó por el lapso de un año. Posteriormente, Jamil Mahuad, fue elegido presidente para gobernar de 1998 a 2002, pero a causa de la crisis de 1999 y las medidas tomadas en su gobierno fue también destituido de su cargo por un triunvirato militar a inicios del año 2000. Por tal motivo, Gustavo Noboa, VicePresidente de la República, asumió la presidencia el 22 de enero del 2000 ante el colapso del gobierno de Mahuad y gobernó hasta el año 2002. 
Luego, en el año 2003 fue electo Presidente de la República de Ecuador, el Cnel. Lucio Gutiérrez, quien también tuvo una presidencia interrumpida al cabo de dos años, siendo destituido por el Congreso Nacional acusado de "abandono del cargo". En su lugar, el Vicepresidente Alfredo Palacio, asumió la presidencia constitucional por sucesión, siendo posesionado por la entonces vicepresidenta del Congreso, Cinthya Viteri, culminando el periodo de gobierno de Gutiérrez. De esta forma se han detallado los seis presidentes que gobernaron el Ecuador en el transcurso de una década, quienes no llegaron a terminar su periodo de gobierno.

Por otra parte, entre los eventos externos de mayor incidencia se pueden considerar los siguientes: las crisis monetarias, financieras y cambiarias de México (1994-1995), del Sudeste Asiático (1997-1998), de Rusia (1998), Brasil (1998-1999), Turquía (2000-2001), Argentina (2001-2002); la volatilidad del precio de exportación del petróleo y su aumento progresivo desde el año 2002; la devaluación del dólar frente al euro desde el 2003; la última crisis inmobiliaria, financiera y económica de los años 2008 y 2009 los cuales constituyen las principales causas que determinaron el panorama macroeconómico ecuatoriano de finales del Siglo XX e inicios del Siglo XXI (Banco Central del Ecuador, 2010).

A fines de 1994, luego de suscribir el Tratado de Libre Comercio (TLC) con Estados Unidos, México sufrió una de las crisis económicas más profundas de su historia contemporánea. Así en este tiempo, el ingreso de capitales especulativos y de inversión directa apreciaron el peso mexicano, las importaciones fueron superiores a las exportaciones, la salida de divisas por la remuneración al capital externo (intereses de los bonos de deuda y utilidades de las empresas extranjeras) se sumó a los déficits comerciales, todo esto deterioró la cuenta corriente de la balanza de pagos y erosionó la capacidad del Banco de México para sostener el tipo de cambio (Rapoport \& Brenta, 2010, pág. 77).

En julio de 1997, luego del traspaso de Hong Kong a China, estalló la crisis del Sudeste Asiático (Corea del Sur, Indonesia, Tailandia, Filipinas, Hong Kong, Singapur, Taiwán y Malasia, cuando el gobierno de Tailandia dejó flotar su moneda, el bath, en medio de un creciente deterioro económico y financiero, provocando la inflación cambiaria, las salidas masivas de capitales y las quiebras de empresas, bancos y particulares (Rapoport \& Brenta, 2010, pág. 82).

En 1998 ocurrió la crisis rusa donde el rublo se devaluó un 26,7\% durante el mes de agosto, mientras que el índice bursátil cayó un $55 \%$ y prácticamente todos los bancos comerciales entraron en crisis de liquidez, ocasionando una parálisis del sistema de pagos, una caída acelerada del sector real de la economía, aumento del desempleo y una fuerte reducción en la calidad de vida de los habitantes (Rapoport \& Brenta, 2010, pág. 88).

De igual manera, en el año 1998 la crisis brasileña provocó ataques especulativos contra el real y las reservas internacionales disminuyeron un $38 \%$ entre septiembre y diciembre. A pesar de las presiones para devaluar, el gobierno adoptó medidas ortodoxas, como el recorte del gasto público y el Banco Central incrementó la tasa de interés del 29,7\% en junio al 42,2\% en diciembre. La Bolsa de Valores de San Pablo cerró en 1998 con una caída del 40\% y los títulos públicos brasileños transados en el exterior cayeron un 20\%. La actividad económica afectada por las altas tasas de interés se desplomó y el desempleo en los estados industriales llegó al 15\% (Rapoport \& Brenta, 2010, pág. 91). 
La crisis turca ocurrió en el año 2001 y fue provocada porque los bancos invertían sus ganancias en bonos estatales, en lugar de conceder préstamos a inversionistas locales, creando de esta manera una economía artificial cuyo crecimiento no dependía de la producción real sino de la especulación financiera y del aprovechamiento del arbitraje cambiario. Por esta razón el gobierno decidió abandonar el sistema de convertibilidad monetaria y sustituirlo por un régimen de libre flotación, lo que provocó que el país entrara en una vorágine hiperinflacionaria con tasas de interés que pasaron del 45\% al 5.000\% (Rapoport \& Brenta, 2010, pág. 94).

Por último, la crisis argentina fue la última de la periferia y el mayor default de deuda soberana de la historia, acompañada por una crisis política y un estallido social de enorme envergadura a finales del 2001 que obligó al Presidente Fernando de la Rúa a presentar su renuncia y en enero 2002 surgió la devaluación del peso y el retorno a un tipo de cambio flexible. Pero esta crisis dejó secuelas de más largo plazo como el deterioro del capital físico y la desindustrialización, así como altos niveles de pobreza y desempleo, etc. (Rapoport \& Brenta, 2010, pág. 97).

Debido a todos estos inconvenientes, tanto internos como externos, por los que atravesaba el Ecuador, sumado a ello, la falta de empleo y el notable crecimiento del subempleo, la decisión de migrar a otros países empezó a rondar por la mente de un gran número de ecuatorianos que se encontraban viviendo una situación inestable en medio de la crisis económica y que buscaban encontrar un empleo fijo y un mejor nivel de vida para sus familias, eligiendo entre los principales destinos, países como Estados Unidos, Italia y España, siendo este último donde se concentró el mayor número de migrantes ecuatorianos, debido principalmente al no requerimiento de visado, a la facilidad del idioma y a una oferta laboral asequible, ya que como se pudo evidenciar en los diferentes informes sobre la situación migratoria de los ecuatorianos, sus labores se habían concentrado en actividades agrícolas, de la construcción y del servicio doméstico principalmente, actividades en las que la mayoría de migrantes se había sumado, especialmente los provenientes de los países andinos.

En este aspecto, Martínez señala que los rasgos internos que presenta la población ecuatoriana se basan en abundante población joven, significancia de los movimientos migratorios a escala interprovincial e interregional, importantes corrientes migratorias del campo a la ciudad y escasa relevancia de los movimientos inmigratorios de carácter internacional. Pero, sin duda, el rasgo que mejor define la situación demográfica ecuatoriana en la actualidad es la emigración internacional, la cual, a pesar de ser bastante cuantiosa, no influye en un descenso de la tasa de crecimiento demográfico (Martínez, 2011).

Como indicara Sánchez, la migración internacional no es un fenómeno nuevo en la historia. El ser humano es migrante por naturaleza y desde la época de los primeros pobladores se conoce que los hombres han estado moviéndose de un lugar a otro con mayor o menor intensidad (Sánchez J. , 2010).

De igual manera, Cagigal señala que los procesos migratorios representan movimientos de las personas que se trasladan de un lugar a otro, ya sea de forma temporal o definitiva, en búsqueda de mejores perspectivas para su vida y la de sus familias. Por lo general, estos flujos se 
originan por condiciones de pobreza, falta de empleo, crisis económica, política o social, situaciones que conllevan a una salida arriesgada hacia lo desconocido con el fin de obtener un mejor futuro (Cagigal, 2010).

Asimismo, la migración de los ecuatorianos a otros países del mundo no es un fenómeno desconocido. Desde la década de 1960, se han conformado redes trasnacionales que contemplaban el flujo de personas, dinero, información, objetos, las cuales han conectado comunidades locales con diversos lugares como Venezuela, Canadá, y especialmente con los Estados Unidos y, desde finales del Siglo XX, con países europeos como España e Italia. A partir de 1998 se distingue un aumento precipitado de la migración y un giro elemental en los perfiles migratorios (Herrera, Carrillo, \& Torres, 2005).

En este sentido se puede indicar que originalmente, la migración de Ecuador se había dirigido sobre todo a Estados Unidos, país de preferencia de nuestros migrantes, manteniendo un crecimiento estable de los mismos. Sin embargo, a partir de la crisis de Ecuador a finales del Siglo XX, la migración ecuatoriana se acelera principalmente a la búsqueda de un empleo para así poder ayudar a la familia y se produce una diversificación en el destino, que incluye a nuevos países europeos, particularmente a España.

La incorporación de España a la Unión Europea, genera la expansión de las empresas españolas y aumenta las oportunidades de empleo sobre todo de mano de obra poco calificada, y dado el contexto de bajo crecimiento poblacional y de envejecimiento de la población española, son numerosos los migrantes de habla castellana, sobre todo de aquellos países, como Ecuador, que vivían crisis económicas internas, resultantes de la denominada "década perdida" de los años ochenta, que se distribuyen entre el "sueño americano" y la ilusión de la huida hacia la "madre patria”, tierra que los recibía con algunas preferencias a los provenientes de otros países más cercanos (Cagigal, 2010).

Por su parte, Zaldívar menciona que durante los últimos años, España se ha transformado en un segmento importante de la proyección internacional de los países latinoamericanos, esto debido a la globalización y a la redefinición de la escena internacional, la necesidad de multilateralizar las relaciones externas ha creado una situación en donde los países de América Latina buscan concretar cierto tipo de afinidades a nivel internacional y de manera especial con el territorio español (Zaldívar, 1997).

Según Zaldívar la participación de España en la Unión europea se convierte en un referente de acción para el desarrollo de su política latinoamericana. Esta situación ha contribuido a que durante la década de los noventa, España y los países latinoamericanos hayan podido establecer numerosos lazos que aseveran el alto nivel alcanzado en las relaciones bilaterales y multilaterales. En lo político se destacan las cumbres iberoamericanas, las constantes visitas de Jefes de Estados y otros altos funcionarios a Madrid y del gobierno español a distintos países latinoamericanos, así como el apoyo brindado por los gobiernos españoles en el proceso de paz en América Latina. En el plano económico, igualmente España es uno de los principales inversionistas en Latinoamérica, la mayor parte de su cooperación internacional se destina a los países de la región, siendo muy significativas las relaciones comerciales entre España y América Latina (Zaldívar, 1997). 
En lo referente a Ecuador, la agenda de las relaciones bilaterales hispano-ecuatorianas se encuentra marcada por el tema migratorio, debido a que la población ecuatoriana en España es la segunda más importante, después de la marroquí, y la primera latinoamericana. Según el padrón del Instituto Nacional de Estadística-INE del 2008, el número de ecuatorianos en España asciende a 458.437 personas.

En este aspecto se puede indicar que a Ecuador le interesa mantener buenas relaciones con España porque aproximadamente el $4 \%$ de su población se encuentra en el territorio español, razón por la cual en el año 2007, en su primera gira oficial por Europa, España fue el primer destino escogido por el presidente ecuatoriano, Rafael Correa, donde fue recibido por el presidente español y el Rey, y en el cual tuvo un protagonismo mayor que en otras ciudades europeas. En el 2008 volvió a viajar a España junto con otras autoridades como la Ministra de Relaciones Exteriores, la Secretaria del Migrante, el Ministro de Defensa, entre otros (Malamud \& García-Calvo, 2009).

El gran flujo de migración desde Ecuador a España ocurre entre 1999 y agosto del 2003, período de la crisis económica del Ecuador, aprovechando el convenio existente entre ambos países, por el que no se requería visa para permanecer tres meses en el país visitado. Durante esos cuatro años la cantidad de migrantes ecuatorianos a España triplicó a la que se dirigió a Estados Unidos (Bertoli, 2010).

Una característica trascendental de la migración ecuatoriana hacia España durante esos años fue la presencia de las redes de familiares y amigos, la misma que fue particularmente importante en el inicio de nuevos destinos migratorios, así como también la importancia significativa de la presencia de la mujer en esas migraciones, cuyo promedio era del $47 \%$ y que luego llegó al 52\% (Cagigal, 2010).

Igualmente, se puede indicar que entre los atractivos de España considerados por los migrantes ecuatorianos, además de la lengua común y la gran brecha económica, salarial y de oportunidades de empleo existente entre ambos países, se consideran también el acceso a los servicios gratuitos de salud y educación para todos los migrantes, la mayor tolerancia social y una actitud predominantemente positiva hacia los inmigrantes, incluyendo a aquellos en situación irregular. A este cambio de destino contribuyeron de igual forma las restricciones crecientes a la migración impuesta por Estados Unidos, así como a los altos costos que pedían los coyoteros por cruzar la frontera, factores que ayudaron a situar a Europa, de manera particular a España, como una opción más atractiva y barata para migrar.

Adicionalmente, es importante mencionar que según un estudio realizado por FlacsoEcuador, Italia es el tercer destino de la migración ecuatoriana, puesto que aproximadamente, el $10 \%$ de nuestros migrantes se encuentran en ese país. Si bien el número de personas es notablemente menor al que fue a Estados Unidos y España, la comunidad ecuatoriana -en ciudades pequeñas como Génova- ha alcanzado importantes proporciones. De acuerdo al segundo Informe de las migraciones de la Comunidad de Génova en el 2005, el número de ecuatorianos con permiso de residencia pasaron de 3.048 en el año 2000 a 10.368 en el 2004 (FLACSO Ecuador, 2008). 
De esta forma, podemos indicar que en estos tres países estaría concentrado el $89 \%$ de los migrantes ecuatorianos, registrando mayor presencia de mujeres en Italia, una paridad en España y mayoría de hombres en Estados Unidos. Aunque también se registran datos de migrantes ecuatorianos en otros países europeos como Inglaterra y Alemania, pero en porcentajes muy bajos.

En este sentido, se puede alegar que la principal causa de la emigración en Ecuador fue el decreciente nivel de vida que llevaban los ecuatorianos, debido a los desafortunados gobiernos de los últimos años, a la inflación y el desempleo, junto a la aguda crisis financiera que vivió el país a finales del Siglo XX, factores que terminaron provocando una de las mayores explosiones migratorias que involucraron a más de dos millones de personas, cifra en realidad alarmante, siendo equivalente a que uno de cada cinco ecuatorianos aproximadamente abandonaba el país, en condiciones difíciles de sobrellevar, dejando solos a sus familiares y particularmente a sus hijos y cónyuges, con la esperanza de encontrar en otros países, las oportunidades que no habían alcanzado en su propia nación.

En cuanto a la inflación, durante los años 90 el índice inflacionario anual empezó en el 49\%, ascendió a 60\% en 1992 y cayó hasta un $23 \%$ en 1995. Posteriormente subió de manera paulatina hasta llegar al 61\% en el año 1999, cerrando la década en el 40\% (Banco Central del Ecuador, 2010).

Respecto al desempleo, de acuerdo con los datos del INEC, de 1992 a 1999, dicho promedio fue de 9,6\%, pero en el año de la crisis (1999), se registró la tasa más alta del periodo, 14,4\%. Sin embargo, en Ecuador también existe el subempleo, que se refiere al empleo inadecuado relativos a la duración y a la productividad del trabajo. De 1992 a 1999 la tasa media de subempleo fue de 56,6\%, pero en el año 1999 dicha tasa llegó al $60.5 \%$ y sumada con la tasa de desempleo $9 \%$, evidencia la situación caótica que se vivió en ese año, puesto que cerca de las dos terceras partes de la Población Económicamente Activa (PEA), esto es, el 69,5\%, no contaba con un trabajo seguro. Razones por las cuales en el año 1999 surgió el acelerado incremento de la salida de ecuatorianos hacia el exterior, registrando un saldo migratorio de 91,108 (INECEcuador, 2000).

Así, los migrantes ecuatorianos conforman una parte significativa de las víctimas que a fines del siglo pasado provocaría una crisis económica y política sin precedentes, teniendo su más grave desenlace en el feriado bancario decretado el 08 de marzo de 1999 durante el gobierno del Dr. Jamil Mahuad Witt, situación que debió enfrentar la población nacional con un costo social en extremo significativo.

Debido a la profundidad de los desequilibrios económicos y la inestabilidad política, el 9 de enero del 2000, el Gobierno Nacional anunció la decisión de adoptar un esquema de dolarización de la economía ecuatoriana con el fin de tranquilizar a la población y controlar su descontento. Esta medida implicaba que la divisa norteamericana sustituya a la moneda local en sus funciones de reserva de valor, unidad de cuenta, y medio de pago. Así, el dólar estadounidense se convierte entonces en la moneda de curso legal y se le prohíbe al BCE emitir nuevos sucres, salvo moneda fraccionaria (Banco Central del Ecuador, 2010). 
De esta manera, el proceso de implementación de la dolarización inició con la fijación del tipo de cambio de 25,000 sucres por dólar, precio al que el BCE canjearía los sucres emitidos en dólares (monedas y billetes). Es importante señalar que para poder realizar este proceso, el BCE disponía de un monto de divisas llamadas Reserva Monetaria Internacional (RMI) cuyo valor a diciembre de 1999 era de \$1,276 millones de dólares. Sin embargo, a partir de la dolarización, el concepto de RMI ha sido reemplazado por el de Reserva Internacional de Libre Disponibilidad (RILD), el cual, si bien es en esencia la misma RMI, ahora actúa como respaldo del total de las especies monetarias (monedas) emitidas por el BCE, así como de los depósitos que el sistema financiero público y privado mantienen en dicho Banco y son los recursos de los que puede disponer inmediata y libremente el Banco Central para cumplir con sus funciones.

En lo referente al sector monetario y financiero, el proceso de dolarización implicó considerables costos, sobre todo una importante transferencia de riqueza de los agentes tenedores de activos en sucres y pasivos en dólares, hacia los agentes tenedores de pasivos en sucres y activos en dólares. Así por ejemplo, una persona que tenía depósitos por 100 mil sucres en el año 1999, pasó a tener depósitos por USD 4 en el año 2000, mientras que un agente tenedor de una deuda equivalente a 100 mil sucres en 1999 pasó a tener una deuda de apenas USD 4 (Banco Central del Ecuador, 2010).

Por otra parte, el Ecuador cuenta con una serie de factores exógenos que le permiten financiar su economía y particularmente sostener la dolarización. Aquí podemos destacar dos recursos más importantes que le confieren al país la liquidez, que son: la venta del petróleo y las remesas enviadas por los migrantes, las cuales constituyen el segundo rubro de los ingresos nacionales. Esta inyección de dinero en forma directa a la economía popular ha restado presión, paralelamente, sobre el Estado en cuanto a la aplicación de programas sociales más intensivos y permanentes. Uno de los efectos económicos inmediatos de la emigración ha sido la recepción de crecientes sumas de dinero enviadas por las personas que han salido del país. Estas remesas contribuyeron a reducir los efectos más agudos de la crisis, al tiempo que desencadenaron otros impactos (Acosta, López, \& Villamar, 2005).

En este sentido, los autores que anteceden señalan que las remesas han experimentado un crecimiento que puede ser clasificado en tres etapas: la etapa de crecimiento inicial que va desde 1993 a 1997 y en la que el incremento anual de remesas promedió los 120 millones de dólares; la segunda etapa que sería de aceleración, entre 1998 y 2000, en la que el aumento anual promedio de remesas se duplicó, alcanzando los 262 millones. Y la tercera etapa, con una tendencia a la saturación, comprendida entre el 2001 y 2004, en la que se desacelera el flujo de remesas, promediando un crecimiento de apenas 64 millones anuales; así en términos reales, en estos años prácticamente no se registró un crecimiento. Observando además, que la aceleración del flujo de remesas en 1998 coincide con el estallido de la última ola migratoria. Sin embargo, no debe olvidarse que la evolución de las remesas no es lineal y que éstas no están garantizadas en forma permanente (Acosta, López, \& Villamar, 2005).

Por su parte, Egüez señala que los niveles de emigración de los ecuatorianos han ido creciendo a lo largo de los años, y hemos llegado a un punto tal que hoy día Ecuador depende económicamente de las remesas enviadas por dichos migrantes. De hecho, sin estas remesas, "la 
dolarización implantada a partir de enero del año 2000 no habría podido sostenerse" (Egüez, 2001).

Además, señala Egüez que el primer impacto que la emigración genera en Ecuador se puede cuantificar objetivamente a través de indicadores económicos, siendo el más adecuado las transacciones de las remesas de los migrantes. Así, conforme han transcurrido los años, las remesas de los migrantes han tenido cada vez mayor importancia en la renta nacional. Según datos del Banco Central de Ecuador (BCE), las remesas de los trabajadores se consideran dentro de las principales fuentes de ingresos corrientes de la nación superando cuantitativamente inclusive al turismo, camarón y banano. El ingreso de las remesas se cataloga después del petróleo y sus derivados como la segunda fuente de ingreso de Ecuador. De aquí se deriva la afirmación de que gracias a tal ingreso la dolarización se ha sostenido (Egüez, 2001).

De igual manera, se puede señalar que con el envío de remesas los migrantes esperaban compensar de alguna manera el impacto social que causaba la migración debido a la separación de las familias y comunidades enteras y mejorar así su nivel de vida y el de sus familiares que se quedaron en Ecuador. Aunque la mayor parte de las remesas recibidas en Ecuador eran utilizadas para el sostenimiento de los gastos básicos de las familias, en algunos casos también han servido para la construcción de viviendas y compra de bienes de consumo, entre los que figuran vehículos y electrodomésticos, lo que permite reactivar la economía del país.

También, estas remesas representaban una fuente importante de financiamiento externo de la balanza de pagos y tuvieron un crecimiento constante desde mediados de los años noventa. En 1995 el Ecuador recibió 382 millones de dólares por concepto de remesas y a partir de 1999 éstas registraron una evidente actividad en la economía ecuatoriana y se convirtieron en el segundo rubro generador de divisas, luego de las exportaciones de petróleo, fortaleciendo la demanda agregada de la economía nacional debido al incremento del consumo de los hogares ecuatorianos, con su respectivo impacto en los niveles de importaciones de bienes de consumo (Acosta, López, \& Villamar, 2005).

Por su parte, Martínez indica que las remesas de los emigrantes constituyen el 15,1\% del ingreso nacional. De acuerdo con el BCE, entre 1990 y 1999, \$4.214 millones de dólares estadounidenses ingresaron al país por concepto de las remesas de los migrantes; de ellos, sólo en el año 1999 se recibieron \$1.101 millones, lo que supone un 25\% del total de la década. Sin embargo, si comparamos esta cifra con el saldo de la balanza comercial de ese año, cuyo monto fue de \$1.714 millones de dólares, se observa que las remesas representan alrededor del $60 \%$ del saldo de la balanza ecuatoriana, lo que demuestra que a partir de ese año los ingresos por este concepto comenzaron a ser significativos para el país. Esta aseveración se respalda además, con el vertiginoso incremento de la salida de ecuatorianos que se dio a partir del año 1999, cuyo saldo migratorio fue de 91,108 según cifras del Instituto Nacional de Estadísticas y Censo INEC.

Así entonces, según afirma Martínez, la economía ecuatoriana se ha mantenido a flote principalmente gracias a los ingresos petroleros y a las remesas enviadas por los migrantes. Si comparamos los beneficios de estas dos fuentes principales de ingresos, las remesas constituyen el 59\% de las exportaciones de crudo ecuatoriano. "Sin duda, sin remesas la economía de 
Ecuador se iría a pique”. La dolarización no ha fracasado debido a las remesas enviadas por los emigrantes a sus familiares, ya que constituyen un soporte monetario adquisitivo sólido con miras hacia la estabilidad y bienestar económico en miles de hogares ecuatorianos. Además, al incrementar su nivel de vida, se hace mayor el ahorro en las familias, junto a una mayor movilidad monetaria en la compra-venta de inmuebles y bienes patrimoniales (Martínez, 2011).

Como se puede observar en el desarrollo de este trabajo, varios autores han manifestado que gracias a las transferencias de dinero remitidas por los migrantes ecuatorianos residentes en el exterior, la dolarización de la economía nacional ha podido seguir adelante y mantenerse por un periodo mayor a quince años. Cabe mencionar que estas aseveraciones se esperan poder comprobarlas más adelante cuando se analicen los valores recibidos por concepto de remesas con el saldo de la balanza comercial ecuatoriana.

De igual manera, es importante mencionar que por sus características productivas, el Ecuador depende esencialmente de las exportaciones petroleras y no petroleras, las primeras incluyen el petróleo crudo y sus derivados y las no petroleras contienen a los productos tradicionales como el banano y plátanos, café, camarón, cacao, atún, pescado y flores naturales, así como también a los productos no tradicionales como la pitahaya.

Según informe del Banco Central, las exportaciones de productos industrializados (alto valor agregado), en promedio desde 1990 hasta el 2012 han representado el $22 \%$ de las exportaciones totales, mientras que las exportaciones de los productos primarios están concentradas en el $78 \%$ en cuatro productos básicos: petróleo crudo, banano, camarón y flores naturales, de los cuales el petróleo tiene la mayor participación, 46\% entre el periodo 1990 1999 y 69\% entre el 2000 y 20012 (Banco Central del Ecuador, 2013).

En cuanto a las importaciones de bienes FOB podemos mencionar que entre los principales productos que Ecuador importa están: bebidas y tabacos, aceites, grasas y ceras de origen animal y vegetal, productos químicos y similares, caucho y sus manufacturas, madera, papel, cartón, cuero, hilos, textiles, vehículos, entre otros. Según informe del Banco Central del Ecuador, las importaciones de acuerdo a la clasificación económica de los productos por uso o destino, durante el periodo 1990 - 2015, han experimentado una tendencia creciente, el mayor aumento se refleja en las materias primas y los bienes de capital. Siendo la serie de importaciones de combustibles y lubricantes la de mayor volatilidad.

Los principales destinos de las exportaciones de Ecuador son los Estados Unidos, Chile, Vietnam, Perú y Colombia, mientras que los países a donde Ecuador importa bienes FOB son: Estados Unidos, China, Colombia, Brasil y Perú.

A continuación se muestra el gráfico No. 2 donde se detalla el análisis de las exportaciones e importaciones ecuatorianas de bienes FOB, así como el saldo de la balanza comercial desde el año 2000, año de inicio de la dolarización, hasta el año 2015. 


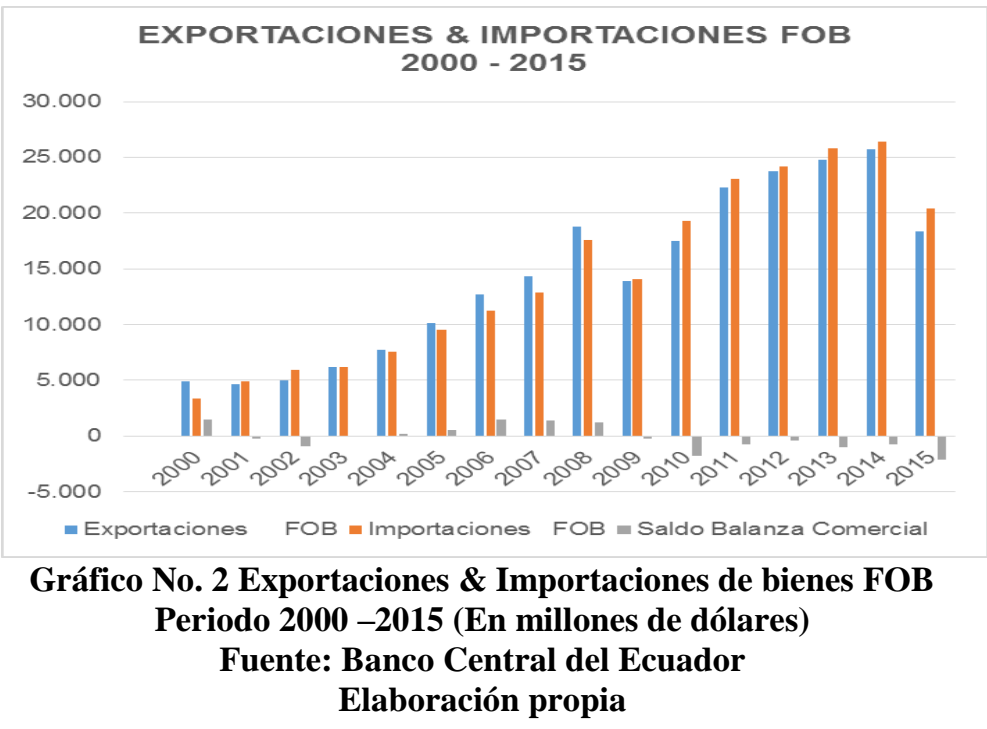

En este gráfico se observa que en el primer año de la economía dolarizada, el Ecuador realizó exportaciones de bienes FOB por un monto de \$4,900 millones de dólares, mientras que las importaciones FOB sumaron $\$ 3,400$, lo que permitió obtener un saldo positivo en la balanza comercial de $\$ 1,500$ millones de dólares.

Durante los tres años posteriores, es decir 2001, 2002 y 2003, el saldo de la balanza comercial fue deficitario, esto se debe a que las importaciones de bienes FOB fueron superiores a las exportaciones efectuadas durante esos años. Así en el 2001, se efectuaron exportaciones de bienes FOB por un valor de $\$ 4,600$ millones de dólares e importaciones FOB por $\$ 4,900$, registrando un saldo en la balanza comercial de (300) millones de dólares.

En el 2002, las exportaciones subieron a \$5,000 millones, pero las importaciones fueron por $\$ 5,900$ millones, es decir que en ese año, el Ecuador importó $\$ 1,000$ millones más que el año anterior, cuando sólo había exportado $\$ 400$ millones más que en el año 2001, por esta razón la diferencia creció a (900) millones de dólares; mientras que en el 2003, se reporta un saldo negativo en la balanza comercial de (5) millones de dólares.

En el periodo 2004 - 2008, las exportaciones de bienes FOB superaron a las importaciones FOB, por lo que el saldo de la balanza comercial reportó superávit durante cinco años consecutivos, permitiendo que el país cuente con suficiente liquidez y que la dolarización de la economía ecuatoriana continúe su curso.

Sin embargo, a partir del año 2009 y hasta el último año de este estudio, el saldo comercial reporta déficit. En el 2010 se observa $(1,788)$ millones en el $2013(1,013)$ millones y finalmente en el 2015, el saldo comercial fue de $(2,116)$ millones de dólares, lo que demuestra que durante el periodo 2009 hasta el año 2015 las importaciones FOB realizadas por el Ecuador han sido superiores a los ingresos obtenidos por la venta de bienes a precios FOB.

Ahora bien, como se había señalado anteriormente, las remesas son los envíos de dinero que efectúan los emigrantes a sus países de origen. Estas constituyen un factor de desarrollo económico para los países de origen de la inmigración y el principal sustento de los familiares 
que se quedaron en el país. Asimismo, las remesas han sido fundamentales para sostener la economía ecuatoriana, puesto que establecen un aporte de divisas para mantener la dolarización. Las remesas fueron tomando cada vez mayor importancia y se convirtieron en el segundo rubro generador de ingresos para el país después del petróleo, principal producto de exportación del Ecuador. Y es precisamente gracias a estas transferencias de dinero recibidas a partir del año 2000, que el país obtuvo liquidez y pudo compensar el saldo deficitario de la balanza comercial. Seguidamente se presenta el gráfico No. 3 donde consta el detalle de los valores recibidos por concepto de remesas durante el periodo $2000-2015$.

En el gráfico 3 se observa que en el año 2000, el Ecuador recibió por concepto de remesas la cantidad de $\$ 1,317$ millones de dólares; en los años 2001 y 2002 ingresaron al país la cantidad de $\$ 1,415$ y $\$ 1,432$ millones, respectivamente, registrando un incremento porcentual del $7 \%$ en relación al año 2000. A partir del año 2003, el ingreso de divisas al país por concepto de remesas siguió creciendo, registrando la cantidad de \$1,627 millones de dólares en ese año. Para el 2005 los valores recibidos sumaron \$2,454, mostrando un incremento del 34\% en relación al año anterior cuyo valor fue de $\$ 1,832$ millones de dólares.

En el año 2007, las remesas de los trabajadores alcanzaron la cifra más alta del periodo de estudio, llegando a los $\$ 3,335$ millones de dólares, equivalente al 7,3\% del PIB. Sin embargo, en el año 2008 se observa una brusca caída del 8\%, es decir que el monto recibido en ese año fue por $\$ 3,083$, lo que se atribuye a la crisis financiera internacional de ese año que causó una fuerte restricción en la actividad económica mundial, provocando el desempleo en los países de mayor afluencia de migrantes ecuatorianos, como son: España, Estados Unidos e Italia. Finalmente, en el periodo 2009 - 2015 se aprecia que el promedio de los ingresos recibidos por este concepto se sitúa en alrededor de los $\$ 2,500$ millones de dólares.

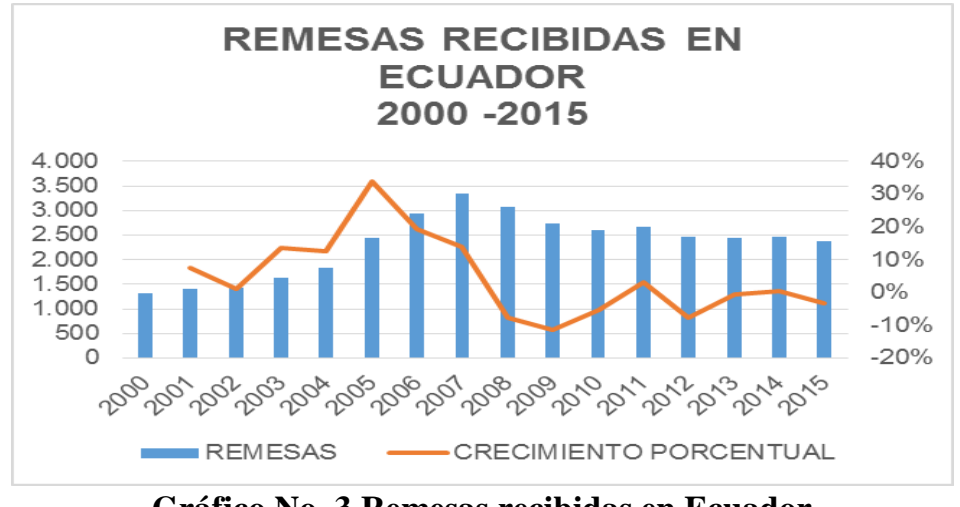

\section{Gráfico No. 3 Remesas recibidas en Ecuador Periodo 2000 -2015 (En millones de dólares) Fuente: Banco Central del Ecuador Elaboración propia}

Así, el envío de remesas por parte de los migrantes ha adquirido un significativo compromiso en la economía ecuatoriana, siendo uno de sus efectos primordiales el incremento de la capacidad adquisitiva de los hogares receptores de divisas, puesto que su incidencia ha sido directa tanto en el aumento del consumo como en el impulso de las actividades emprendedoras por parte de los beneficiarios de las mismas. En relación a este tema, según Carlos Alberto Correa, gerente general de "Famiremesas Ecuador", empresa localizada en la ciudad de 
Guayaquil, dedicada a la transferencia de dinero, indica que alrededor del $50 \%$ de las transacciones de las remesas provienen de los Estados Unidos, un 30\% de España y un 20\% del resto del mundo. En el Ecuador existen varias empresas que se dedican a que las remesas lleguen a su destino, es decir a manos de los familiares beneficiarios de sus parientes que residen en el extranjero. Algunas de estas empresas son: Delgado Travel, Western Union, DHL, Agencia Costamar, Money Gram, RIA, Mateo Express, Gran Manzana Poblana, entre otras. Sin embargo, esto se ha convertido en un gran negocio en donde se cobra alrededor de 10 y 27 dólares por cada 300 dólares remitidos a sus parientes (Egüez, 2001).

Por otra parte, la consolidación de este fenómeno trajo consigo la proliferación de nuevos servicios financieros, como son las cooperativas que surgieron en las provincias ecuatorianas con mayor índice de emigración (Azuay, Cañar y Guayas). Mientras que los bancos sólo actuaron como canales de envío, las cooperativas aprovecharon esta oportunidad para convertirse en canalizadoras del ahorro enviado por los migrantes ecuatorianos desde el exterior.

Pero el Ecuador no es el único país de la Región que se ha beneficiado con el ingreso correspondiente a las remesas enviadas por los migrantes. En los países de la Comunidad Andina de Naciones, las remesas obtuvieron un promedio anual de crecimiento del 9,6\% en el periodo 2001 - 2010, pasando de $\$ 4,298$ millones de dólares recibidos en el año 2001 a $\$ 9,815$ millones en el 2010, donde Ecuador recibió el 24\% del total de remesas, convirtiéndose en el tercer receptor de remesas de América del Sur, situándose sólo por detrás de Colombia (41\%) y de Perú (26\%) (Secretaría General Comunidad Andina de Naciones, 2011). Según este organismo, las remesas han permitido que los hogares con bajos recursos tengan ingresos adicionales, permitiéndoles mejorar su calidad de vida, tener mayor acceso a los servicios de salud y educación, así como incrementar los niveles de consumo e inversión. Entre los principales países de origen que envían remesas a la Comunidad Andina están: Estados Unidos con \$3,445 millones de dólares, España con \$3,196 millones e Italia con \$523 millones de dólares, representando el 35\%, 33\% y 5\% respectivamente, del total de las remesas durante el año 2010.

Además, se puede indicar que según un informe realizado por el Fondo Multilateral de Inversiones (FOMIN) del Banco Interamericano de Desarrollo (BID) y el Pew Hispanic Center (PHC), aproximadamente un millón de ecuatorianos, que representa el 14\% de la población adulta, reciben remesas por parte de sus familiares que residen fuera del país. El monto total de estas remesas corresponden a \$1,500 millones de dólares anuales, cifra que aumenta aceleradamente. Esta suma elevada de remesas es enviada en miles de transacciones con montos relativamente pequeños, siendo el promedio mensual de las transferencias recibidas por remesas en Ecuador \$175 dólares, donde la mitad de los beneficiarios de estas divisas obtuvieron abonos inferiores a la media, mientras que sólo el $31 \%$ de los receptores recogieron cantidades superiores a esta cifra (Bendixen \& Associates, 2003).

Respecto a los beneficiarios receptores de estas transferencias, un estudio reveló que un $28 \%$ de las remesas se asignó a los padres o suegros que se quedaron al cuidado de los hijos de los migrantes, mientras que el $22 \%$ fue recibido directamente por los hijos de los emigrantes y apenas el $6 \%$ fue entregado a los cónyuges, lo que se puede atribuir tanto a las reagrupaciones familiares como a la separación de los mismos (Olivié \& Ponce, 2008). 
En cuanto al destino final de estas divisas recibidas por los familiares de los migrantes, las investigaciones señalan que la mayoría de los receptores $(61 \%)$ utilizó las remesas para cubrir los gastos de primera necesidad de sus hogares como: alimentación, alquiler, pago de servicios básicos, transporte, compra de ropa y medicinas. Mientras que el 17\% de los beneficiarios de las remesas las usó en gastos superfluos o lujos y el 22\% restante de los favorecidos, empleaba el dinero recibido en inversiones como compra de terrenos o construcción de propiedades, negocios, educación, ahorros, etc. (Acosta, López, \& Villamar, 2005).

De esta manera, indica Acosta, estos recursos dieron oxígeno a la economía ecuatoriana, en especial a las provincias meridionales de la Sierra, como Azuay, Cañar y Loja, donde 6 de cada 10 habitantes tienen algún familiar residiendo en el exterior. En esas provincias ingresaron unos $\$ 650$ millones de dólares, de los más de $\$ 1,300$ millones registrados en el año 2000. Se estima que en ese año más del $55 \%$ de las remesas totales recibidas en Ecuador fueron receptadas en esas zonas, seguidas de la provincia del Guayas que obtuvo el $10 \%$ y las provincias de Manabí y Pichincha con un 5\% cada una (Acosta, López, \& Villamar, 2005). Por lo tanto se puede inferir que en lineamientos generales, las remesas enviadas por los emigrantes ecuatorianos que se encuentran en el exterior han logrado reactivar la economía local de una manera muy eficaz, generando el consumo de los habitantes e incentivando en la pequeña y mediana empresa. A continuación se muestra el Gráfico No. 4 donde se compara el saldo de balanza comercial con las remesas enviadas por los migrantes ecuatorianos que residen fuera del país durante el periodo 2000 - 2015.
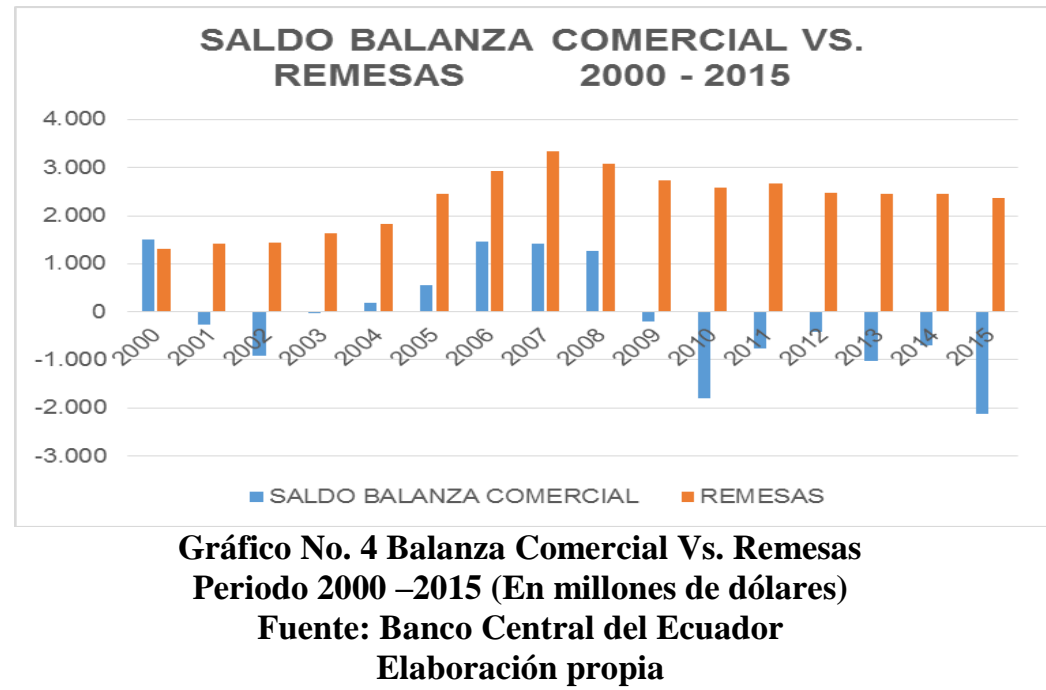

En el gráfico No.4 se puede apreciar que en el año 2000 el saldo de la balanza comercial del Ecuador registró valores por \$1,500 millones de dólares, mientras que los ingresos recibidos en el país por concepto de las remesas enviadas por los migrantes ecuatorianos residentes en el exterior fueron por $\$ 1,300$ millones de dólares, lo que demuestra que en ese año, el saldo comercial superó a los ingresos recibidos por concepto de remesas en \$200 millones de dólares.

Para el año 2001, el saldo de la balanza comercial muestra una brusca caída del $117 \%$, en comparación al año anterior, registrando un valor negativo de \$260 millones de dólares, en cambio el monto ingresado por remesas en ese año, aumentó su valor en \$100 millones, es decir 
que dicho monto fue por \$1,400 millones de dólares. Así, en ese año el dinero enviado por los migrantes ecuatorianos contribuyó para que el país cuente con suficiente liquidez para poder cumplir con sus obligaciones financieras y salvaguardar la dolarización de la economía ecuatoriana.

En el año 2002 el saldo comercial continuó reportando cifras negativas, acrecentando su valor en un $255 \%$ en relación al año anterior, siendo el saldo comercial de ese año (917) millones de dólares, lo que significa que las importaciones superaron a las exportaciones de bines FOB en dicho monto, mientras tanto las transferencias recibidas por remesas sumaron $\$ 1,430$ millones de dólares, manteniendo un crecimiento sostenido en los valores recibidos por este concepto durante los tres primeros años de la dolarización.

En el año 2003 se puede notar que aunque el saldo de la balanza comercial continúa siendo deficitario, reflejando la cantidad de (5) millones de dólares, la diferencia porcentual bajó del 255\% registrados en el año 2002 al 99\%, mientras que los valores receptados en calidad de remesas continuaron creciendo, recibiendo en ese año la cantidad de \$1,630 millones de dólares, lo que demuestra que en el transcurso del año 2003 el Ecuador recibió un 14\% más de ingresos por concepto de remesas de los migrantes ecuatorianos.

En el periodo 2004 - 2008, se puede notar que el saldo de la balanza comercial ecuatoriana fue aumentando progresivamente registrando superávit durante los cinco años consecutivos, lo que manifiesta que las exportaciones superaron a las importaciones de bienes FOB durante todos esos años. De igual manera el dinero acogido por concepto de remesas en el país fue creciendo paulatinamente, recibiendo transferencias por $\$ 1,830, \$ 2,450$ y $\$ 2,930$ millones de dólares durante los años 2004, 2005 y 2006, respectivamente, mientras tanto en el año 2007 el Ecuador receptó por concepto de remesas la cantidad de \$3,335 millones de dólares, siendo éste el año de mayor transferencias recibidas durante el periodo de estudio.

En el año 2008 el saldo comercial reportó cifras por \$1,265 millones de dólares registrando una caída del $11 \%$ en relación al año anterior, asimismo los valores ingresados al país en calidad de remesas presentan una brusca caída del $8 \%$, es decir que el monto recibido en ese año fue por $\$ 3,083$, situación que se imputa a la crisis financiera internacional de ese año, la misma que provocó limitaciones en la actividad comercial de los países desarrollados en los cuales se encontraban residiendo los migrantes ecuatorianos.

Finalmente, durante los últimos seis años del periodo de estudio (2009 - 2015) se aprecia que tanto el saldo de la balanza comercial ecuatoriana, como los ingresos recibidos por concepto de remesas continuaron decreciendo. Así el saldo comercial en el 2009 fue de (208) millones de dólares, en el año 2010 pasó a ser (1,790) millones, para el 2011 se contabilizan (760) millones, en el año 2012 observamos un saldo de (415) millones, en el 2013 tuvimos un monto de $(1,015)$ millones, en el año 2014 el saldo se aproxima a los (700) millones y en el 2015 se registra un saldo comercial deficitario por $(2,116)$ millones de dólares.

Por su parte, se observa que los valores recibidos por concepto de remesas en el año 2009 fueron por \$2,736 millones de dólares, en el 2010 se receptaron \$2,592 millones, para el 2011 el dinero remitido por los migrantes totalizaron los \$2,672 millones, en el 2012 las transferencias 
ingresadas al país bajaron a \$2,466 millones, en el 2013 las remesas continuaron decreciendo registrando un monto de $\$ 2,449$ millones, en el 2014 las divisas sumaron $\$ 2,461$ millones y en el año 2015 el monto recibido por remesas fue de \$2,377 millones de dólares.

Como hemos podido apreciar en el gráfico No. 4 -Saldo Balanza Comercial vs. Remesasdurante el periodo 2000 - 2015, los valores recibidos por concepto de remesas enviadas por los migrantes ecuatorianos desde el exterior superan de forma notoria a los datos registrados en el saldo de la balanza comercial del Ecuador, el mismo que corresponde a la diferencia entre las exportaciones y las importaciones de bienes a precios FOB que realizó el país durante dicho periodo. Observando además, que mientras la curva de la balanza comercial es muy inestable y presenta caídas bruscas durante los años post dolarización de la economía ecuatoriana, las remesas en cambio, muestran un crecimiento sostenido durante los primeros ocho años del periodo de estudio, aunque a partir del año 2009 se aprecia una disminución de los valores recibidos en este rubro.

\section{Conclusiones}

La crisis financiera, económica y política que sufrió el Ecuador a finales del Siglo XX provocó un efecto negativo en la calidad de vida de la población ecuatoriana, debido a diversos factores como: los altos índices de inflación, la devaluación de la moneda local, el aumento del desempleo y el notable crecimiento del subempleo, que presionaron a que más de dos millones de conciudadanos tomaran la decisión de emigrar hacia países desarrollados como Estados Unidos, España e Italia, en búsqueda de un empleo fijo y un mejor nivel de vida para sus familias.

En este ciclo migratorio, España fue el país de preferencia de los migrantes ecuatorianos debido al convenio existente entre ambos países por el que no se requería visa para permanecer tres meses en dicho país y que además les permitía a los ecuatorianos tener acceso a la nacionalidad española con dos años de residencia legal en ese país, así como también la facilidad del idioma y a una oferta laboral asequible para desarrollar principalmente actividades agrícolas, de la construcción y del servicio doméstico. Por esta razón, cerca de medio millón de ecuatorianos se encuentran residiendo actualmente en el territorio español. En el año 2000, debido a la profundidad de los desequilibrios económicos y la inestabilidad política, el Gobierno Nacional decidió dolarizar la economía ecuatoriana con un tipo de cambio de 25.000 sucres por dólar, con el fin de tranquilizar a la población y controlar su descontento. Así, el dólar estadounidense se convierte entonces en la moneda de curso legal y se le prohíbe al Banco Central emitir nuevos sucres, salvo monedas fraccionarias.

Por otra parte, con el empleo obtenido por miles de compatriotas en el exterior, se generaría el mayor beneficio que recibiría el Ecuador entero fruto de esa masiva partida, el envío de las remesas necesarias para sustentar a sus familias, pero además y de forma simultánea para respaldar el proceso de dolarización de la economía ecuatoriana llevado adelante tras el feriado bancario de marzo de 1999.

A finales de la década de los noventa, las remesas registraron una evidente actividad en la economía ecuatoriana y se convirtieron en el segundo rubro generador de divisas, luego de las exportaciones de petróleo, fortaleciendo la demanda agregada de la economía nacional debido al 
incremento del consumo de los hogares ecuatorianos, con su respectivo impacto en los niveles de importaciones de bienes de consumo. En el año 2007, las remesas de los trabajadores alcanzaron la cifra más alta del periodo de estudio, llegando a los $\$ 3,335$ millones de dólares, equivalente al 7,3\% del PIB. De igual manera, se puede señalar que con el envío de remesas los migrantes esperaban compensar de alguna manera el impacto social que causaba la migración debido a la separación de las familias y de comunidades enteras y mejorar así su nivel de vida y el de sus familiares que se quedaron en Ecuador.

Al mismo tiempo, la economía ecuatoriana se sostiene por la exportación de los productos petroleros y no petroleros por los cuales recibe ingresos en dólares que respaldan la dolarización, sin embargo el país también importa bienes FOB lo que ocasiona que los dólares salgan hacia el exterior. Durante el periodo 2000 - 2015, se ha podido observar que las importaciones han superado a las exportaciones, por lo que el saldo de la balanza comercial ha sido deficitario. Es aquí precisamente donde se aprecia el aporte de los migrantes ecuatorianos hacia el sostenimiento del sistema económico financiero vigente en el país, a través del envío de dinero desde los países donde se encuentran residiendo, logran estabilizar la liquidez que sustenta una economía dolarizada.

Finalmente, se advierte al concluir este trabajo coincidiendo con las opiniones manifestadas por otros autores, respecto a que sin las remesas enviadas por los migrantes ecuatorianos, la dolarización de la economía ecuatoriana no hubiese podido mantenerse. Esta afirmación surge al efectuar el análisis comparativo entre los valores registrados en el saldo de la balanza comercial con los montos recibidos por concepto de remesas, donde se pudo observar que las remesas superan de forma notoria al saldo de la balanza comercial durante los últimos quince años, siendo este rubro esencialmente el que ha permitido que el Ecuador continúe con la dolarización de su economía.

Sin embargo, acerca de este panorama, podría mencionarse que ante una economía como la ecuatoriana, con un déficit de su balanza comercial sostenido y permanente, así como con una disminución paulatina en los envíos de remesas de parte de los migrantes connacionales, el gobierno ecuatoriano debería dedicar todos sus esfuerzos a fomentar las exportaciones a la par de impulsar una reducción de sus importaciones, lo que permitiría obtener un saldo positivo alcanzando mayor ingreso de divisas. Mantener dolarizada la economía ecuatoriana sin ningún tipo de planificación gubernamental que permita conseguir más divisas del exterior teniendo en cuenta siempre que las remesas han empezado a decaer con el pasar de los años, según la evidencia empírica analizada en el periodo post dolarización, podría instituir un muy difícil escenario para la economía ecuatoriana en el mediano plazo.

\section{Bibliografía}

Acosta, A., López, S., \& Villamar, D. (2004). Ecuador: Oportunidades y Amenazas Económicas de la Emigración. En F. Hidalgo, Migraciones, Un juego con cartas marcadas (págs. 259-302). Quito: Ediciones Abya-Yala.

Acosta, A., López, S., \& Villamar, D. (2005). Las remesas y su aporte para la economía ecuatoriana. FLACSO-Ecuador, 227-252.

Arízaga, L. (2005). La política del estado ecuatoriano hacia los emigrantes nacionales. En J. Ponce, 
Emigración y Política Exterior en Ecuador (págs. 21-56). Quito: ABYA-YALA.

Banco Central del Ecuador. (2001). La dolarización en el Ecuador. Un año después. Quito: Banco Central del Ecuador (BCE).

Banco Central del Ecuador. (2010). La Economía Ecuatoriana Luego de 10 Años de Dolarización. Quito: Dirección General de Estudios BCE.

Banco Central del Ecuador. (2013). Estadísticas Macroeconómicas. Presentación Estructural. Quito: Dirección de Estadística Económica del BCE.

Barriga, L. (2012). La protección de las situaciones de quiebra económica de particulares. Un desafío para los servicios sociales de España. Revista Internacional de Trabajo Social y Bienestar, 2138.

Bartolomé, M. (2015). Relaciones entre España y América Latina en el ámbito de la Defensa. Revista de Relaciones Internacionales, Estrategias y Seguridad, 111-131.

BBVA. (13 de 03 de 2017). Banco Bilbao Vizcaya Argentaria. Obtenido de https://www.bbva.com/es/

Beckerman, P., \& Solimano, A. (2003). Crisis y Dolarización en el Ecuador: Estabilidad, Crecimiento y Equidad Social. Washington D.C.: The World Bank.

Bendixen \& Associates. (2003). Receptores de Remesas en Ecuador. Una investigación del mercado. Quito: Fondo Multilateral de Inversiones-FOMIN del BID, Pew Hispanic Center-PHC.

Bertoli, F. H. (2010). Immigration Policies and the Ecuadorian Exodus. IZA Discussion Paper No. 4737, 1-29.

Cagigal, J. (2010). "Migración y desarrollo: el caso de Ecuador-España". Observatorio de la Economía Latinoamericana, No. 141, http://www.eumed.net/cursecon/ecolat/ec/2010/.

Calduch Cervera, R. (2002). La Política Exterior de España. Balance y Perspectivas. Madrid: Fundación Global Democracia y Desarrollo.

Callejo, S. (2013). La pretensión de la ejecución hipotecaria. Madrid, España: Universidad Nacional de Educación a distancia.

Castedo, P. (2012). Análisis económico de la dación en pago. Docta Ignorancia Digital, 3-19.

CEMLA - BID. (2010). Programa de mejora de la información y procedimientos de los bancos centrales en el área de remesas, Remesas internacionales en Ecuador. México, D.F.: CEMLA - BID.

Colectivo IOÉ. (2007). La inmigración ecuatoriana en España. Una visión a través de las fuentes estadísticas. En E. Gómez, A. Tornos, \& Colectivo-IOÉ, Ecuatorianos en España. Una aproximación sociológica (págs. 179-230). Madrid: Subdirección General de Información Administrativa y Publicaciones. 
Diario El Comercio. (20 de 02 de 2013). Diario El Comercio. Obtenido de http://www.elcomercio.com/actualidad/mundo/plan-retorno-migrantes-ecuatorianosespana.html

Domínguez, A. (2015). La mediación en los procesos de desahucios. Mediación hipotecaria. Mediatio, $35-42$.

Egüez, A. (2001). "Las remesas de emigrantes en Ecuador tras la dolarización". Observatorio de la Economía Latinoamericana.

Embajada del Ecuador en España. (30 de Junio de 2016). Ministerio de Relaciones Exteriores y Movilidad Humana. Obtenido de http://espana.embajada.gob.ec/es/

FLACSO Ecuador. (2008). Ecuador: La migración internacional en cifras. FLACSO Ecuador, 1-93.

García-Calvo, C. (2006). Las relaciones bilaterales España-Ecuador: situación actual y perspectivas de futuro. Quórum. Revista de pensamiento iberoamericano, No. 15, 122-135.

Gil-Alonso, F., Bayona i Carrasco, J., \& Vono De Vilhena, D. (2012). Las migraciones internas de los latinoamericanos en España: del boom a la crisis económica. Papeles de Población, Vol. 18, núm. 71, 1-42.

Gómez, E. (2001). Ecuatorianos en España: historia de una inmigración reciente. Ecuador Debate, No. 54, 175-188.

Gómez, E. (2007). Ecuatorianos en España: Claves de un proceso inmigratorio en cuatro tiempos. En E. Gómez, A. Tornos, \& Colectivo-IOÉ, Ecuatorianos en España. Una aproximación sociológica (págs. 15-99). Madrid: Subdirección General de Información Administrativa y Publicaciones.

Goycoechea, A., \& Ramírez, F. (2002). Se fue, ¿a volver?Imaginarios, familia y redes sociales en la migración ecuatoriana a España (1997-2000). Íconos, FLACSO Ecuador, 32-45.

Granda, D. (2004). El Presidencialismo en el Ecuador. Revista ideológico política Tendencia, 78-86.

Hernández, R. (2010). Metodología de la Investigación, Quinta Edición. Mexico D.F.: Mc Graw-Hill.

Herrera, G., Carrillo, M., \& Torres, A. (2005). La migración ecuatoriana, transnacionalismo, redes e identidades. Quito: FLACSO.

Herrera, G., Moncayo, M., \& Escobar, A. (2012). Perfil migratorio del Ecuador 2011. Quito: Organización Internacional para las Migraciones (OIM).

Iglesias, J., Moreno, G., Fernández, M., Oleaga, J., \& Vega, F. (2015). La población de orígen ecuatoriano en España. Características, necesidades y expectativas en tiempos de crisis. Madrid: Freepress S. Coop. Mad.

INEC-Ecuador. (1998). Anuario de Entradas y Salidas Internacionales. Quito: INEC-ECUADOR. 
INEC-Ecuador. (2000). Anuario de Entradas y Salidas Internacionales. Quito: INEC-ECUADOR.

INEC-Ecuador. (2001). VI Censo de Población y V de Vivienda. Quito: INEC.

Lekanda, P. (2009). El conflicto territorial entre Ecuador y Perú por el Río Del Cenepa 1995: Entre una mediación fallida y otra exitosa. Pléyade No. 4, 186-211.

Malamud, C., \& García-Calvo, C. (2009). La política exterior de Ecuador: entre los intereses presidenciales y la ideología. América Latina-ARI No.61, 1-8.

Martínez, C. (2011). El Papel de la Emigración en la situación socioeconómica de Ecuador. Nimbus No. 27-28, 77-94.

Méndez, R., \& Julio, P. (2016). Crisis inmobiliaria y desahucios hipotecarios en España: Una perspectiva geográfica. Boletín de la Asociación de Geógrafos Españoles No. 71, 99-127.

Miguez, P. (2009). "El nacimiento del Estado Moderno y los orígenes de la Economía Política". Nómadas. Revista Crítica de Ciencias Sociales y Jurídicas, No. 22, 1-21.

Ministerio de Asuntos Exteriores. (2001). Acuerdo entre el Reino de España y la República del Ecuador relativo a la regulación y ordenación de los flujos migratorios. Madrid: Boletín Oficial del Estado.

Ministerio de Asuntos Exteriores y de Cooperación. (7 de Febrero de 2011). Boletín Oficial del Estado - BOE No. 32. Obtenido de http://www.exteriores.gob.es

Ministerio de Asuntos Exteriores y de Cooperación. (30 de 04 de 2017). Gobierno de España. Obtenido de http://www.exteriores.gob.ec

Ministerio de Asuntos Exteriores y de Cooperación-España. (2016). Ficha País Ecuador. Madrid: Oficina de Información Diplomática.

Ministerio de Relaciones Exteriores y Movilidad Humana. (11 de Abril de 2016). Embajada del Ecuador en España. Obtenido de http://espana.embajada.gob.ec/es/

Mollar, M., \& Vilar, S. (2013). El consumidor frente a la ejecución hipotecaria. Revista Jurídica de la Región de Murcia, 1-40.

Montero, G. (2006). Las representaciones sociales de los emigrantes ecuatorianos en España sobre el proceso migratorio. Alternativas: cuadernos de trabajo social No. 14, 35-48.

Olivié, I., \& Ponce, J. y. (2008). Remesas, Pobreza y Desigualdad. El caso de Ecuador. Fundación Real Instituto Elcano de Estudios Internacionales y Estratégicos, 40.

Palma, M., \& Ruíz, A. (2016). Estrategias resilientes ante la situación adversa de los desahucios. Cuadernos de Trabajo Social, 299-308.

Pedone, C. (2002). Las representaciones sociales en torno a la inmigración ecuatoriana a España. Íconos-FLACSO Ecuador No. 14, 56-66. 
Ponce, J. (2005). Emigración y política exterior en Ecuador. En J. Rosenberg, Gestión diplomática del Ecuador en Asuntos Migratorios en Organismos Internacionales (págs. 58-95). Quito: ABYAYALA.

Rapoport, M., \& Brenta, N. (2010). Las grandes crisis del capitalismo contemporáneo. Buenos Aires: Le Monde diplomatique "el Diplo". Capital Intelectual.

Resolución Corte Nacional de Justicia-Ecuador, Juicio No. 167-2009 (Sala Especializada de lo Penal, Penal Militar, Penal Policial y Tránsito 29 de Mayo de 2014).

Revista Avance. (4 de Enero de 1999). Revista Avance. Obtenido de http://www.revistavance.com

Sabaté, I. (2016). La ruptura de una economía moral y la deslegitimación de las deudas hipotecarias. Nómadas. Revista crítica de ciencias sociales y jurídicas, 103-117.

Sánchez, J. (2006). Hipotecas, salarios y crisis financiera. Cuadernos de Economía, 101-144.

Sánchez, J. (2010). Socioeconomía de las Migraciones en un mundo globalizado. Madrid: Biblioteca Nueva, S. L.

Secretaría General Comunidad Andina de Naciones. (10 de Junio de 2011). Estadísticas de Remesas en la Comunidad Andina. Informe Anual. Obtenido de http://extranet.comunidadandina.org/eportal/contenidos/2284_8.pdf

SENAMI. (03 de 05 de 2017). Secretaría Nacional del Migrante - SENAMI. Obtenido de www.unicef.org

Shaikh, A. (1991). Valor, Acumulación y Crisis. Capítulo 6. Bogotá: Tercer Mundo.

Suárez, M. (2014). Movimientos Sociales y Buen Vivir: ecuatorianos en la lucha por la vivienda en la plataforma de afectados por la hipoteca (PAH). Revista de Antropología Experimental, 71-89.

Torres, J. (2009). Crisis inmobiliaria, crisis crediticia y recesión económica en España. Papeles de Europa, 82-107.

Vasilachis, I. (2006). Estrategias de investigación cualitativa. Barcelona: Gedisa S.A.

Vega, M. (2015). España un país hipotecado. Dendra Médica. Revista de Humanidades, 228-239.

Verdesoto, L. (2012). La Región Andina y España: hacia una reformulación de sus relaciones. En A. Cortés, La política migratoria española en los contextos andinos: el caso de Ecuador y España (págs. 71-94). Quito: FLACSO Ecuador.

Zaldívar, A. (1997). Iberoamérica y España: unidad de sentido. Síntesis, 15. 